\title{
Herding Behavior in China Housing Market
}

\author{
Ting $\operatorname{Lan}^{1}$ \\ ${ }^{1}$ Department of Finance and Business Economics, University of Macau, Macau, China \\ Correspondence: Ting Lan, Room: B1-A308, Faculty of Business Administration, University of Macau, Av. Padre \\ Tomas Pereira, Taipa, Macau, China. Tel: 853-6322-7837. Email: olivialan@umac.mo
}

Received: November 11, 2013

Accepted: November 26, $2013 \quad$ Online Published: January 23, 2014

doi:10.5539/ijef.v6n2p115

URL: http://dx.doi.org/10.5539/ijef.v6n2p115

\begin{abstract}
The essay utilizes a unique dataset of 30 Chinese provinces and municipal cities residential selling prices from 1998 to 2013, and examines the herding behavior. Using a least squares method and quantile regression method, we study the herding effect of China housing market at both national and cities levels. Results show that herding formation is stronger in increasing markets than that in decreasing markets. But when the markets are turning turbulent, in the high quantile regression, there is herding activity in decreasing markets. Our results also support the asymmetry of herding behavior in increasing and decreasing markets. By examining the financial crisis on the level of herding behavior, investors in China residential housing markets tend to herd before the crisis, and there is no herding behavior during and after financial crisis by quantitle regression. This study is important for three main reasons. Firstly, although the existing theoretical and empirical studies have investigated abnormal increasing price of China housing market, to the best of author knowledge, we are the first to apply this method to investigate herding phenomena in China housing market, which this essay focuses. Secondly, due to China residential housing market unique characteristics, this study makes a first attempt to examine the herding behavior by using quantile regression. Thirdly, our studies of this paper extend our knowledge of China real estate market to practitioners, academia and policymakers.
\end{abstract}

Keywords: herding behavior, Chinese residential housing market, quantile regression, increasing and decreasing markets, financial crisis

\section{Introduction}

In recent financial literature, the decision making process of market participants has been received considerable empirical testing by academia and practitioners. Numerous papers have been turned to study and focus on the herding activities in global stock markets. For example, Chang, Cheng and Khorana (2000) indicate that there is significant evidence of herding in Taiwan and South Korea and partial evidence of herding in Japan. But they didn't find herding behavior exists in the Hong Kong and US stock markets. Zhou and Lai (2009) focus on Hong Kong stock market and found out herding is prevalent when trading small stocks and investors prefer to herd when selling stocks rather than buying stock. Tan et al. (2008) investigate recent Chinese stock markets and their empirical examine results show that herding occurs under both up and down market conditions. And it is more profound in A-share investors. Scharfstein and Stein (1990) typically define "Herding" as the elusive phenomenon that individuals prefer to follow others in thinking, feeling, and taking actions, while ignoring their own original decisions. Bikhchandani and Sharma (2000) refer herding behavior as an obvious intent by investors to imitate the behavior of other investors. Zhou and Anderson (2013) investigate the market-wide herding behavior in US REIT market and their findings show that herding behavior in real estate markets usually refers to environment in which investors or residential buyers learn and imitate others in the course of investing in REIT market, which lead them to impulsively buy or sell property. Then the REIT market will eventually increase or decrease during the same period of time.

The academic literature on herding has been conducted on both theoretical and empirical research. On the one hand, theoretical research falls into the following four types: concern for reputation, payoff externality, information cascade, and compensation structures. Scharfstein and Stein (1990) concern herding behavior can occur in fund managers or analysts based on their reputation concern. Graham (1999) has also developed theoretical models for reputation based herding. Diamond and Dybvig (1983) refer to the payoff externality by which an investor's withdraw or investment behavior may affect the utility of other agents, which may lead to bank-runs. Banerjee (1992) proves that poor aggregation of information cascade lead investors to neglect real 
values and instead follow the market, which eventually leads to market inefficiency. Bikhchandani, Hirshleifer and Welch (1992) mention that public pool of information grows, is peculiar, and easily crash. Maug and Naik (1996) indicate that the junior fund managers "deviate from return-maximizing portfolio allocations and follow those of their benchmark that shows a herding phenomenon."

On the other hand, empirical research can be classified into two groups. The first group focuses on group-wide herding. That is the tendency of individuals or certain groups of investors, such as mutual fund managers or financial analysts, to follow each other and trade the same assets at the same time. Lakonishok, Shleifer and Vishny (1992) provide the first study that used the method to examine the herding behavior on institutional investors and verify the correlation in trading patterns for a particular group of traders and their tendency to buy or sell the same set of stocks. Grinblatt, Titman and Wermers (1995) improve the LSV model and later on Wermers (1999) develops a portfolio-change measure (PCM) to test herding by considering the direction and intention of investors. The second group focuses on the existence of market-wide herding, which is the collective behavior of all participants towards market views to buy or sell particular assets at the same time. Christie and Huang (1995, hereafter $\mathrm{CH}$ ) provide the first study that proposes an approach to detect whether the herding behavior is presented in the market-wide sense. The $\mathrm{CH}$ method considers the market impact of herding is measured by dispersion, the cross sectional standard deviation (CSSD) of returns. If the market-wide herding occurs, returns on individual stocks would be more than usually clustered around the market return as investors suppress their private opinion in favor of market consensus. Demirer and Kutan (2006) use CH method to test Chinese stock market and get the results that investors are following their private information during investment. Chang, Cheng, and Khorana (2000, hereafter $\mathrm{CCK}$ ) propose a modification to the $\mathrm{CH}$ model, and define the cross-sectional absolute standard deviation (CSAD) and examine an international stock market. In this model, CCK proves the nonlinearity relationship between dispersion and market return. Using the method, CCK find herding behavior exists in emerging market other than developed market. Following the CCK method, Tan et al. (2008) and Chiang et al. (2010) find evidence of herding behavior within China stock markets.

In this paper, we investigate the herding behavior in China residential market, which is one of the prosperous emerging markets in the world. The China real estate market was established in year 1998, a short period of less than 15 years. In July 1998, central government announced the notice on the deepening of housing reform and fastened housing construction policy, which stipulated the welfare-housing distribution system, was abolished; all cities implemented the policy of house monetization allocation and residents need to buy commercial apartments in the residential property trading market. Since the real estate market structure is not perfect, it is common for investors or buyers to imitate the actions of one another. In the real estate market, there is tendency to follow previous successful investment choices, which is called "following the leader", this house prices go up and down together in different provinces or cities can be considered as herding behavior. According to the China National Statistics Bureau, the average growth rate of investment and abnormal increasing of housing prices make people think China real estate market is overheated. The China Ministry of Construction always issues a series of adjustment measures for a rational and healthy development of the real estate market. Besides the growing importance of the real estate market, we observe there is a very little herding literature for China real estate market. Based on the above issues, there are therefore good reasons to detect the herding for China residential housing market.

In this paper, we examine whether market-wide herding behavior exists within China residential housing market from the CCK approach and quantile regression $(\mathrm{QR})$ method. Using 30 provinces and municipal cities residential housing data, we find evidence of herding formation in national wide market. The results help policymakers to implement necessary policies to suppress the abnormal increasing housing prices in different cities.

The remainder of this paper is organized as follows. Section 2 presents the methodology used to detect herding behavior. Section 3 describes the data. Section 4 reports the empirical results of herding behavior based on the least squares estimator and also presents a quantile regression method and applies it to estimate the herding equation. Section 5 concludes the paper.

\section{Methodology}

As mentioned earlier, Christie and Huang (1995, CH) and Chang et al. (2000, CCK) have proposed methods to detect herding behavior in equity return data. $\mathrm{CH}$ proposed that the market impact of herding is measured by considering dispersion - the cross sectional standard deviation (hereafter CSSD) of returns. This measure shows that the stock returns spread around the average market returns. If the market wide herding occurs, returns on individual stocks would be more than usually clustered around the market return as investors suppress their private information in favor of market consensus. CSSD is defined as: 


$$
C S S D_{t}=\sqrt{\frac{\sum_{i=1}^{n}\left(R_{i, t}-R_{m, t}\right)^{2}}{n-1}}
$$

Where $N$ is the total number of stocks in the market portfolio, $R_{i, t}$ is the return of stock $i$ at time $t$, and $R_{m, t}$ is the average return of the market portfolio at time $t$. The rationale is that if herding is prevalent during periods of market stress, returns on individual stocks would be more than those usually clustered around the market return because investors who suppress their private opinions in the market generally favor. $C S S D_{t}$ is then regressed as follow:

$$
C S S D_{t}=\alpha+\beta_{1} D_{t}^{L}+\beta_{2} D_{t}^{U}+\varepsilon_{t}
$$

Where $D_{t}^{L}$ and $D_{t}^{U}$ are the dummy variables which respectively represent market returns that lie in the extreme lower or upper tail of the distribution on day $t$, and equal to zero otherwise; hence $\alpha$ is the mean market return. The presence of negative and statistically significant $\beta_{1}$ and $\beta_{2}$ would indicate the existence of herding.

$\mathrm{CH}$ approach has drawbacks. Since it required defining the extreme returns first, and it also ignores the fact that herding could take place during normal periods. Additional challenge takes place when applying this method to China residential housing market data because of the relatively short history of the market, it is difficult to identify when extreme return occur.

Chang, Cheng and Khorana (2000, CCK) propose a modification to the CH model, CCK model is a more sensitive means of detecting herding by noting that the $\mathrm{CH}$ model is a more stringent test method because it requires "a far greater magnitude of non-linearity" in order to find evidence of herding, CCK used the cross-sectional absolute standard deviation (CSAD), which is calculated as

$$
\operatorname{CSAD}_{t}=\frac{1}{N} \sum_{i=1}^{N}\left|R_{i, t}-R_{m, t}\right|
$$

Where, $R_{i, t}$ is the return on any asset $i$ of the $N$ assets, $R_{m, t}$ represents the return on the market portfolio. Furthermore, the expected cross-sectional absolute deviation (ECSAD) in period $t$ as follows:

$$
E\left(C S A D_{t}\right)=\frac{1}{N} \sum_{i=1}^{N}\left|\beta_{i}-\beta_{m}\right| E_{t}\left(R_{m}-\gamma_{0}\right)
$$

Where, $\gamma_{0}$ is the return on a zero-beta portfolio, $\beta_{i}$ is the time-invariant systematic risk measure of a security, $i=1 \ldots \mathrm{N}$ and $t=1 \ldots T, \beta_{m}$ denotes the time-invariant systematic risk measure of an equally-weighted market portfolio, and $E_{t}()$ denotes the expectation operator in period $t$. The time-varying market equity return and dispersion can be shown in a linear and increasing function, because:

$$
\frac{\partial E\left(C S A D_{t}\right)}{\partial E_{t}\left(R_{m}\right)}=\frac{1}{N} \sum_{i=1}^{N}\left|\beta_{i}-\beta_{m}\right|>0
$$

And

$$
\frac{\partial^{2} E\left(C S A D_{t}\right)}{\partial E_{t}\left(R_{m}\right)^{2}}=0
$$

CCK considered that if herding exists, the nonlinearity inherent in the relationship between dispersion and market return can be written into the new herding equation:

$$
C S A D_{t}=\alpha+\gamma_{1}\left|R_{m, t}\right|+\gamma_{2} R_{m, t}^{2}+\varepsilon_{t}
$$

Where, the coefficient $\left(\gamma_{2}\right)$ of the quadratic item is found to be negative and statistically significant, and then we can say herding is existed. It also allows testing the degree of herding in up versus down market by running the following empirical equations:

$$
\begin{gathered}
C S A D_{t}^{u p}=\alpha+\gamma_{1}^{u p}\left|R_{m, t}^{u p}\right|+\gamma_{2}^{u p}\left(R_{m, t}^{u p}\right)^{2}+\varepsilon_{t}, \text { if } R_{m, t}>0 \\
C S A D_{t}^{\text {down }}=\alpha+\gamma_{1}^{\text {down }}\left|R_{m, t}^{\text {down }}\right|+\gamma_{2}^{\text {down }}\left(R_{m, t}^{\text {down }}\right)^{2}+\varepsilon_{t} \text {, if } R_{m, t}<0
\end{gathered}
$$

\section{Data}

We obtain data on residential housing prices for 30 individual provinces and municipal cities across China over the 
period March, 1998 to May, 2013. The overall residential housing market price is collected as well. The monthly data source comes from economy research institute of Chinese urban and rural construction. With monthly frequency, our sample has 183 observations. Our analysis focuses on these provinces and cities, they are Beijing, Tianjin, Shanghai, Chongqing, Jilin, Heilongjiang, Liaoning, Hebei, Shandong, Jiangsu, Zhejiang, Fujian, Guangdong, Hainan, Guangxi, Anhui, Jiangxi, Hubei, Hunan, Sichuan, Guizhou,Yunnan, Henan, Shaanxi, Shanxi, Inner Mongolia, Gansu, Qinghai, Ningxia and Xinjiang. The return for individual provinces or cities and the overall market portfolio are calculated as $R_{t}=\ln \left(P_{t}\right)-\ln \left(P_{t-1}\right)$ and then $C S A D_{t}$ of equation (3) as the measure of cross-sectional return dispersion.

Table 1 presents the summary statistics of the two variables at monthly data frequency. As shown in the table, the mean of return $R_{m}$ remains positive, and the return dispersion CSAD shows significant skewness and kurtosis, and is not normally distributed. This indicates that OLS method is not effective to test the herding; we should use robust estimation method to test for herding.

Table 1. Summary statistics of $R_{m}$ and CSAD for China residential housing market

\begin{tabular}{llllllll}
\hline & $N$ & Mean & Min & Max & S.D. & Skewness & Kurtosis \\
\hline$R_{m}$ & 182 & 0.007 & -0.123 & 0.263 & 0.051 & 2.228 & 10.662 \\
$C S A D_{t}$ & 182 & 1.466 & 0.000 & 6.242 & 1.452 & 1.364 & 4.037 \\
\hline
\end{tabular}

This table reports the summary statistics of the cross sectional average return $\left(R_{m}\right)$ and the cross sectional absolute deviations (CSAD) for China residential housing market at monthly data frequencies. The data are obtained from the Economy research institute of Chinese urban and rural construction. They range from the start of Mar. 1998 to May. 2013. "N" is the number of data points. "Min" and "Max" are respectively the minimum and maximum data values. "S.D" is the standard deviation.

\section{Empirical Results}

\subsection{Estimates of Herding Behavior}

Table 2 reports the estimation results of herding based on Equation 7. We focus on the herding coefficient $\gamma_{2}$; a negative value on the coefficient $\gamma_{2}$ suggests the existence of herding. The results based on the estimated equation for China residential housing market has high explanatory power, as the R-square is 0.672 , the coefficient on the market return square $\gamma_{2}$ display negative sign and statistically significant at the $1 \%$ level. This finding provides strong support for the existence of herding behavior in the market.

Table 2. Analysis of herding behavior in China residential housing market

\begin{tabular}{lllll}
\hline Market & $\gamma_{0}$ & $\gamma_{1}$ & $\gamma_{2}$ & $R^{2}$ \\
\hline Monthly & & & & \\
OLS & 0.484 & 50.783 & -140.679 & 0.672 \\
& $(5.66)^{* *}$ & $(12.80)^{* *}$ & $(-6.93)^{* *}$ &
\end{tabular}

This table reports the following regression results for China residential housing market: $C S A D_{t}=\alpha+\gamma_{1}\left|R_{m, t}\right|+\gamma_{2} R_{m, t}^{2}+\varepsilon_{t}$. Where $R_{m, t}$ is the cross sectional average return, and $C S A D_{t}$ is the cross sectional absolute deviations of returns. The sample period is from Mar, 1998 to May.2013. **represents statistical significance at the $5 \%$ level.

\subsection{Herding under Up And Down Markets}

Recent empirical research (Tan et al., 2008; Chiang \& Zheng, 2010) highlights the asymmetric characteristics of asset return. The evidence shows substantiate asymmetric herding behavior under different market conditions. In our paper, it is also interest to examine whether herding behavior presents an asymmetric reaction on months when the market is rising vis-à-vis months when the market is falling. Therefore, we can rewrite equation (8) and (9) into the following expression:

$$
\operatorname{CSAD}_{t}=\gamma_{0}+\gamma_{1}(1-D)\left|R_{m, t}\right|+\gamma_{2} D\left|R_{m, t}\right|+\gamma_{3}(1-D) R_{m, t}^{2}+\gamma_{4} D R_{m, t}^{2}+\varepsilon_{t}
$$

Where the dummy variable $\mathrm{D}=1$ if $R_{m, t}<0$ and $\mathrm{D}=0$ if otherwise. 
Table 3 presents the regression estimated asymmetric herding coefficient under up and down markets conditions. We find a negative sign $\left(\gamma_{3}\right)$ for the herding coefficient in up market. However, the estimated coefficient of $\gamma_{3}$ is not statistically significant. The evidence is to support that the herding can be only found in the down market. We also test the equality of the herding coefficient between the up and down markets and conduct Wald test by subtracting coefficient on the decreasing market from the coefficient on the increasing market. $\left(\gamma_{3}-\gamma_{4}=0\right)$. The Chi-squared statistics, as shown in the last column of Table 3, indicating the null hypothesis of $\gamma_{3}-\gamma_{4}=0$ can be rejected. Therefore, we can consider the herding effect appears to be stronger during down markets than during up markets.

Table 3. Contains regression estimation results of herding in the up and down markets

\begin{tabular}{cccccccc}
\hline \multirow{2}{*}{ Market } & \multicolumn{2}{c}{$\gamma_{0}$} & \multicolumn{2}{c}{$\underline{\text { Up Market }}$} & \multicolumn{2}{c}{ Down Market } & \multicolumn{2}{c}{$\gamma_{3}-\gamma_{4}=0$} \\
& & $\gamma_{1}$ & $\gamma_{3}$ & $\gamma_{2}$ & $\gamma_{4}$ & $\chi^{2}$ \\
\hline Monthly & 1.015 & 27.861 & -43.942 & 5.691 & -3.08 & 0.73 & 44.247 \\
OLS & $(9.75)^{* *}$ & $(4.27)^{* *}$ & $(-1.33)$ & $(3.23)^{* *}$ & $(-2.90)^{* *}$ & $(0.000)^{* *}$ \\
\hline
\end{tabular}

This table reports the following regression results for China residential housing market:

$C S A D_{t}=\gamma_{0}+\gamma_{1}(1-D)\left|R_{m, t}\right|+\gamma_{2} D\left|R_{m, t}\right|+\gamma_{3}(1-D) R_{m, t}^{2}+\gamma_{4} D R_{m, t}^{2}+\varepsilon_{t} \cdot$

Where the dummy variable $\mathrm{D}=1$ if $R_{m, t}<0$ and $\mathrm{D}=0$ if otherwise. $R_{m, t}$ is the cross sectional average return, and $C_{S A D}$ is the cross sectional absolute deviations of returns. The sample period is from Mar, 1998 to May.2013. $\chi^{2}$ is the Chi-squared statistic with one degree of freedom for the Wald test. Numbers in parentheses are t-statistics based on Newey-West (1987) consistent standard errors. ** represents statistical significance at the $5 \%$ level.

\subsection{Quantile Regression Method and Results}

It is generally recognized that least squares estimation is a mean based regression method. When there are statistical problems exist, such as non-normal distribution, sensitivity to outliers, and errors in variables, the least squares method will have estimation bias. However, Barnes and Hughes (2002) argue that these problems can be alleviated by using quantile regression (Koenker \& Bassett, 1978). Comparing with least squares method, QR is able to analysis the entire distribution of the dependent variable. For detailed technical discussion about this method, readers can refer to Koenker 2005. In the previous section (Table 1), we have found that the return dispersion (CSAD) is non-Gaussian distribution; the statistics shows significant skewness and kurtosis. Therefore, we should consider quantile regression, which is more robust and efficient than the ordinary least squares method (Buchinsky, 1998).

Quantile regression is a statistical procedure, which estimates the full range of conditional quantile functions. (Koenker, 2005). The linear conditional quantile function is written as:

$$
Q Y_{i}\left(\tau / X_{i}\right)=\alpha(\tau)+X_{i}^{\prime} \beta(\tau)+\mu_{i}(\tau)
$$

Where $Y_{i}$ is the dependent variable, $X_{i}{ }^{\prime}$ is a vector of independent variables and $\beta(\tau)$ is a vector of coefficient, and $\mu_{i}(\tau)$ is the error term. $(\tau) \sim(0,1)$ indicates the quantile. The $\beta(\tau)$ can be found out by minimizing weighted sum least absolute errors:

$$
\beta_{\tau}(\tau)=\underset{\beta}{\operatorname{argmin}}\left(\sum_{i: Y_{i}>\alpha(\tau)+X_{i}^{\prime} \beta(\tau)}\left|Y_{i}-\alpha(\tau)-X_{i}^{\prime} \beta(\tau)\right| \tau+\sum_{i: Y_{i}<\alpha(\tau)+X_{i}^{\prime} \beta(\tau)}\left|Y_{i}-\alpha(\tau)-X_{i}^{\prime} \beta(\tau)\right|(1-\tau)\right)
$$

The function (12) illustrates that the quantile regression coefficient can be got by minimizing the weighted sum least absolute errors, where the weights are dependent on the quantile values. When $\tau=0.5$, the quantile regression becomes the median regression. Other common quantiles are 0.1 th quantile, $0.25^{\text {th }}$ quantile, $05^{\text {th }}$ quantile, $0.75^{\text {th }}$ quantile and $0.9^{\text {th }}$ quantile. We use these quantiles to estimate the relationships among the dependent variable and independent variables. Thus in our research paper, the method provides a complete picture in helping us to understand the relation between dispersion and cross sectional market returns. The linear programming can be solved by using the software Eviews8. In our research equation, we use quantile regression method to test the CSAD and a set of independent variables $X_{i}$, the $\tau$ quantiles are characterized as:

$$
\operatorname{QCSAD}_{\tau, t}=\gamma_{o, \tau}+\gamma_{1, \tau}(1-D)\left|R_{m, t}\right|+\gamma_{2, \tau} D\left|R_{m, t}\right|+\gamma_{3, \tau}(1-D) R_{m, t}^{2}+\gamma_{4, \tau} D R_{m, t}^{2}+\varepsilon_{\tau, t}
$$

Where in equation (13), $\mathrm{D}$ is a dummy variable by setting $\mathrm{D}=1$, if $R_{m}$ is less than zero, and $\mathrm{D}=0$ if otherwise. 
The estimation is using quantile regression which is based on the distributions of the dependent variable and the estimations use the sample points conditional on a specific quantile. Thus, the quantile regression is more efficient and appropriate for real estate return that presents a skewness distribution.

Table 4 reports the quantile regression results of herding in China residential housing market. We find overall significant and negative sign of $\gamma_{2}$ across quantiles. Based on the QR results, the evidence shows that the herding exists in the market during Mar., 1998 to May, 2013.

Table 4. Analysis of herding in China residential housing market by quantile regression

\begin{tabular}{lllll}
\hline Market & $\gamma_{0}$ & $\gamma_{1}$ & $\gamma_{2}$ & Pseudo $R^{2}$ \\
\hline$\tau=10 \%$ & 0.00 & 32.03 & -76.79 & 0.387 \\
& $(0.00)$ & $(4.32)^{* *}$ & $(-1.84)$ & \\
$\tau=25 \%$ & 0.00 & 39.36 & -83.33 & 0.366 \\
& $(0.00)$ & $(5.57)^{* *}$ & $(-2.46)^{* *}$ & \\
$\tau=50 \%$ & 0.26 & 47.73 & -111.85 & 0.415 \\
& $(3.63)^{* *}$ & $(10.18)^{* *}$ & $(-5.56)^{* *}$ & \\
$\tau=75 \%$ & 0.67 & 62.00 & -174.01 & 0.485 \\
& $(5.67)^{* *}$ & $(8.50)^{* *}$ & $(-6.24)^{* *}$ & \\
$\tau=90 \%$ & 1.30 & 63.21 & -185.31 & 0.484 \\
& $(8.26)^{* *}$ & $(8.76)^{* *}$ & $(-7.35)^{* *}$ & \\
\hline
\end{tabular}

This table reports the following regression results for China residential housing market:

$C S A D_{t}=\alpha+\gamma_{1}\left|R_{m, t}\right|+\gamma_{2} R_{m, t}^{2}+\varepsilon_{t}$

Where $R_{m, t}$ is the cross sectional average return, and $C S A D_{t}$ is the cross sectional absolute deviations of returns. The sample period is from Mar, 1998 to May, 2013. **represents statistical significance at the $5 \%$ level.

Table 5. Analysis of herding in up and down markets by quantile regression

\begin{tabular}{|c|c|c|c|c|c|c|c|}
\hline \multirow{2}{*}{ Market } & \multirow{2}{*}{$\gamma_{0, \tau}$} & \multicolumn{2}{|c|}{$\underline{\text { Up Market }}$} & \multicolumn{2}{|c|}{ Down Market } & \multirow{2}{*}{ Pseudo $R^{2}$} & \multirow{2}{*}{$\begin{array}{c}\gamma_{3}-\gamma_{4}=0 \\
\chi^{2}\end{array}$} \\
\hline & & $\gamma_{1, \tau}$ & $\gamma_{3, \tau}$ & $\gamma_{2, \tau}$ & $\gamma_{4, \tau}$ & & \\
\hline \multirow[t]{2}{*}{$\tau=10 \%$} & 0.00 & 30.13 & -67.35 & 1.00 & 0.00 & 0.222 & 0.044 \\
\hline & $(0.00)$ & $(2.88)^{* *}$ & $(-1.16)$ & $(1.90)$ & $(0.00)$ & & \\
\hline \multirow[t]{2}{*}{$\tau=25 \%$} & 0.33 & 21.58 & -12.46 & 0.46 & 0.19 & 0.185 & $9.859 * *$ \\
\hline & $(4.11)^{* *}$ & $(2.63)^{* *}$ & $(-0.37)$ & $(0.58)$ & $(0.42)$ & & \\
\hline \multirow[t]{2}{*}{$\tau=50 \%$} & 0.43 & 36.26 & -69.91 & 22.90 & -11.73 & 0.239 & $6.407 * *$ \\
\hline & (1.66) & $(3.59)^{* *}$ & $(-1.74)$ & $(0.61)$ & $(-0.59)$ & & \\
\hline \multirow[t]{2}{*}{$\tau=75 \%$} & 1.02 & 40.45 & -94.49 & 45.41 & -23.83 & 0.374 & $9.565^{* *}$ \\
\hline & $(3.17)^{* *}$ & $(5.40)^{* *}$ & $(-3.43)^{* *}$ & $(1.60)$ & $(-1.59)$ & & \\
\hline \multirow[t]{2}{*}{$\tau=90 \%$} & 1.42 & 53.45 & -149.78 & 55.99 & -29.55 & 0.411 & $1.15^{* *}$ \\
\hline & $(5.77)^{* *}$ & $(7.57)^{* *}$ & $(-5.87)^{* *}$ & $(3.74)^{* *}$ & $(-3.76)^{* *}$ & & \\
\hline
\end{tabular}

This table reports the following regression results for China residential housing market:

$$
Q C S A D_{\tau, t}=\gamma_{o, \tau}+\gamma_{1, \tau}(1-D)\left|R_{m, t}\right|+\gamma_{2, \tau} D\left|R_{m, t}\right|+\gamma_{3, \tau}(1-D) R_{m, t}^{2}+\gamma_{4, \tau} D R_{m, t}^{2}+\varepsilon_{\tau, t}
$$

Where the dummy variable $\mathrm{D}=1$ if $R_{m, t}<0$ and $\mathrm{D}=0$ if otherwise. $R_{m, t}$ is the cross sectional average return, and $C S A D_{t}$ is the cross sectional absolute deviations of returns. Sample period is from Mar, 1998 to May, 2013. $\chi^{2}$ is the Chi-squared statistic with four degree of freedom for the Wald test. Numbers in parentheses are t-statistics based on Newey-West(1987) consistent standard errors.**epresents statistical significance at the $5 \%$ level. 


\subsection{Asymmetric Effects of Different Market Conditions}

Using the OLS method, we have found a negative sign $\left(\gamma_{3}\right)$ for the herding coefficient in up market. However, the estimated coefficient of $\gamma_{3}$ is not statistically significant. The previous result shows that there exists an asymmetric effect in the market. Next, we use Quantile regression, the more robust method to examine whether investors or buyers behave asymmetrically with up and down market conditions. To do so, the sample is divided into an increasing or up market return means $R_{m}>0$, and a decreasing or down market return means $R_{m}<0$. The results are shown in Table 5.

From the Quantile regression (Buchinsky, 1998) result, we can see that when market is trending up, herding would exist. Because of the up markets, investors saw profits all the time, and there are always have positive feedback on investing the housing market. Therefore, the herding is very significant during this time.

One possible explanation for an asymmetry in herding between up and down markets is the flow of positive and negative information. In China, the real estate developers tend to issue more buying recommendations actively than selling recommendations, and housing buyers or investors have less knowledge and experience with the reasonable house prices, and act differently on the recommendations, but when the market prices drop down much quickly, we could observe more herding in the down market. Another possible explanation is the China residential housing market is known to be guided by government policy; the Chinese government frequent intervenes in the asset markets when the house prices increases dramatically.

In order to cool down the abnormal housing market returns, Chinese government raises interest rates six times within six months in year 2011. The National People's Congress (NPC) passed the $12^{\text {th }}$ five year plan of 2011-2015 in March 2011. The central government issued the regulations that local governments should help build up 36 million units of public housing in next five years. First tier cities or provinces follow the strict implementations or regulations. In Shanghai and Chongqing, the local governments announced the property tax on trial basis, so residents in these two cities pay taxes on new residential housing purchases after July, 2011. Besides that, in Beijing the local government banned the sale of homes to those who have not lived in Beijing for five years. Beijing also limited the number of homes a native Beijing family could own two, and allowed only one home for non-native Beijing families. Comparing with these big cities, other second tier cities or provinces act on slowly. When the market average return decline $\left(R_{m}<0\right)$, the herding is significant in the market.

We also find an interesting result is that $\gamma_{4, \tau}$ achieves significant negative at high quantiles. (e.g., $\tau=90 \%$ ) The high quantile means the market is more turbulent, and the market-wide housing prices are having big movements. As we discussed before, in order to suppress the abnormal increasing of housing prices, the central government imposed strict monetary policy and various implementations, such as increase mortgages rate and down payment, banned more homes buying nationwide, imposed property taxes for in big cities, and build up public housing within five years (2011-2015).

According to the CREIS (2012) "CREIS Hundred Cities Price Index" that was published on April $13^{\text {th }}$, 2012, it was comparing with Mar. 2011, the overall price of China One Hundred representative cities decreased by $0.34 \%$. There are eight months continuous decreasing of house prices trend since Sep. 2011. In these 100 representative cities, there are only 29 cities housing prices increases, and 71 cities housing prices decreases significantly.

The empirical results are corresponding with the official news; it shows that during the periods of extreme turbulent, the more volatile condition, the more likely the herding behavior exists. Since the local governments are strictly implementing the central government housing price control policy, the more overall market prices decrease, which will cause the more likely to herd.

\subsection{The Financial Crisis on the Level of Herding Behavior}

Recall that herding behavior may occur when the market is highly uncertainty. Previous academic papers include Zhou and Anderson (2013), Chiang and Zheng (2010) and many research scholars have investigated the magnitude of the herding behavior may be higher during a global financial crisis since the overall situation is highly uncertain. Using the cross countries stock markets data, Chiang and Zheng (2010) confirm that herding behavior is more apparent for the developed countries and this phenomenon is less obvious in developing countries during the financial crisis. Christie and Huang (1995) suggest that herding will be more prevalent during the periods of market stress. In this section, we need to use both OLS and QR methods to investigate the financial crisis on the level of herding behavior in China residential housing market.

As we have seen that during the global financial crisis, there are extreme return movements which resulted in collapse of large financial institutions, the bailout of banks by national government, bankruptcy of multinational companies, and worldwide stock markets downturns. In many countries, the housing markets are also suffered. 
Because of prolonged unemployment, a significant decline in global economy activity, and decline in national citizens wealth, market stress eventually lead to a severe global economic recession in 2008.

Although the global financial crisis and downturns happened in 2008 have brought temporary damage to the real estate market and stock market in China, Chinese central government and central bank responded with unprecedented fiscal stimulus on November $9^{\text {th }}, 2008$. The $2008-2009$ Chinese economic stimulus plans is a RMB 4 trillion stimulus package, which is an attempt to minimize the impact of the global financial crisis. The stimulus provided funds for infrastructure projects and housing developments. This will drive employments in areas of manufacturing, steel, cement and other sectors of the economy. Due to the success of the stimulus plan, the central government in 2011 has tightened regulations in the financial systems on banks to raise the mortgage rate and reduce the fear of a property bubble.

The sample period is set from Jan. 2008 to Dec. 2008 as the period of financial crisis. The years before 2008 are established as the period before the financial crisis, while Jan., 2009 to May, 2013 is considered to be the period after the financial crisis. Table 6 and 7 illustrate the results by OLS and QR method respectively.

From Table 6, the market appears to be irrational before and after the financial crisis. The significant and larger negative coefficient of herding before the global financial crisis shows that China residential housing market is exhibiting herding behavior. In contrast, the herding coefficient is not significant during the global financial crisis. Furthermore, there is negative and significant coefficient of herding after the crisis. According to our previous discussion, the OLS may be inappropriate to examine the herding, as we can see from the LM test for autocorrelation, the test statistics significant indicate autocorrelation. Therefore, the OLS has test bias on the following results.

Table 6. The levels of herding before, during and after the global financial crisis by OLS

\begin{tabular}{|c|c|c|c|c|c|c|c|c|}
\hline \multirow{2}{*}{ Market } & \multirow{2}{*}{$\gamma_{0}$} & \multicolumn{2}{|c|}{ Before } & \multicolumn{2}{|c|}{ During } & \multicolumn{2}{|c|}{ After } & \multirow{2}{*}{$R^{2}$} \\
\hline & & $\gamma_{1}$ & $\gamma_{4}$ & $\gamma_{2}$ & $\gamma_{5}$ & $\gamma_{3}$ & $\gamma_{6}$ & \\
\hline Monthly & 0.48 & 60.14 & -197.04 & 8.65 & 492.12 & 34.42 & -67.76 & 0.70 \\
\hline OLS & $(5.57)^{* *}$ & $(11.45)^{* *}$ & $(-5.64)^{* *}$ & $(0.24)$ & $(-0.87)$ & $(5.77)^{* *}$ & $(-2.43)^{* *}$ & \\
\hline
\end{tabular}

Serial Correlation LM Test: Obs*R-squared: 67.755. Prob.Chi-Square(12) 0.00000. This table reports the following regression results for China residential housing market:

$C S A D_{t}=\gamma_{0}+\gamma_{1} D 1\left|R_{m t}\right|+\gamma_{2} D 2\left|R_{m t}\right|+\gamma_{3} D 3\left|R_{m t}\right|+\gamma_{4} D 1 R_{m t}^{2}+\gamma_{5} D 2 R_{m t}^{2}+\gamma_{6} D 3 R_{m t}^{2}+\varepsilon_{t}$

D1 represents the period before the most recent global financial crisis (Mar.1998-Dec.2007); D2 represents during the crisis itself (Jan.2008-Dec.2008); and after the crisis (Jan.2009-May, 2013).The sample period is from Mar, 1998 to May, 2013. ** represents statistical significance at the $5 \%$ level.

In Table 7, we use Quantile regression method to examine the results. The herding coefficient for the pre-crisis period $\gamma_{4}$ is found to be negative and significant during the most quantiles. The evidence shows herding exist before the financial crisis taking place in China residential housing market. Several additional empirical findings are also worth noting. First, during the financial crisis, the evidence suggests that there is no herding activity in the market. The reason is that the financial crisis often causes structural break. The investors might rationalize themselves away from a high loss during a bad circumstance and not to follow the market signal to buy or sell houses. Second, turning to the after financial crisis period, the herding coefficient $\gamma_{6}$ is found to be negative but not significant. That means there is also no herding existed after financial crisis. This is an interesting point comparing with OLS regression. So based on the above results, the empirical evidence seems consistent with the previous discussion about China economic stimulus plans and central government announced various strict implementations and regulations on China housing market. Because of the government effective and efficiency policy measurement during the last three years, the herding phenomenon is not significant in the markets comparing with the stronger herding behavior before the global financial crisis. The results are also opposite from the international assets markets, where the herding behavior is more apparent in the crisis period. 
Table 7. The levels of herding before, during and after the global financial crisis by QR

\begin{tabular}{|c|c|c|c|c|c|c|c|c|}
\hline \multirow{2}{*}{ Market } & \multirow{2}{*}{$\gamma_{0}$} & \multicolumn{2}{|c|}{ Before } & \multicolumn{2}{|c|}{ During } & \multicolumn{2}{|c|}{ After } & \multirow{2}{*}{$\begin{array}{c}\text { Pseudo } \\
R^{2}\end{array}$} \\
\hline & & $\gamma_{1}$ & $\gamma_{4}$ & $\gamma_{2}$ & $\gamma_{5}$ & $\gamma_{3}$ & $\gamma_{6}$ & \\
\hline \multirow[t]{2}{*}{$\tau=10 \%$} & 0.00 & 31.64 & -44.64 & 23.62 & 303.82 & 32.03 & -76.79 & 0.41 \\
\hline & $(0.00)$ & $(4.74)^{* *}$ & $(-1.30)$ & $(1.40)$ & (1.34) & $(3.77)^{* *}$ & $(-1.58)$ & \\
\hline \multirow[t]{2}{*}{$\tau=25 \%$} & 0.05 & 43.77 & -106.65 & 28.00 & 233.56 & 34.39 & $(-76.90)$ & 0.39 \\
\hline & $(0.53)$ & $(6.32)^{* *}$ & $(-2.87)^{* *}$ & $(1.24)$ & $(-0.77)$ & $(2.95)^{* *}$ & $(-1.06)$ & \\
\hline \multirow[t]{2}{*}{$\tau=50 \%$} & 0.30 & 64.65 & -217.62 & 10.58 & 426.97 & 26.72 & -31.62 & 0.46 \\
\hline & $(3.52)^{* *}$ & $(5.96)^{* *}$ & $(-3.75)^{* *}$ & $(0.43)$ & $(1.29)$ & $(2.99)^{* *}$ & $(-0.95)$ & \\
\hline \multirow[t]{2}{*}{$\tau=75 \%$} & 0.64 & 82.77 & -316.89 & -24.13 & 1215.4 & 43.54 & -100.51 & 0.54 \\
\hline & $(5.42)^{* *}$ & $(8.90)^{* *}$ & $(-6.96)^{* *}$ & $(-0.98)$ & $(2.33)$ & $(8.88)^{* *}$ & $(-5.02)$ & \\
\hline \multirow[t]{2}{*}{$\tau=90 \%$} & 1.25 & 77.87 & -290.92 & -72.14 & 1869.7 & 45.61 & -117.40 & 0.54 \\
\hline & $(8.58)^{* *}$ & $(8.52)^{* *}$ & $(-5.17)^{* *}$ & $(-3.47)$ & $(4.56)$ & $(9.29)^{* *}$ & $(-6.28)^{*}$ & \\
\hline
\end{tabular}

This table reports the following regression results for China residential housing market:

$Q C S A D{ }_{t}=\gamma_{0}+\gamma_{1} D 1\left|R_{m t}\right|+\gamma_{2} D 2\left|R_{m t}\right|+\gamma_{3} D 3\left|R_{m t}\right|+\gamma_{4} D 1 R_{m t}^{2}+\gamma_{5} D 2 R_{m t}^{2}+\gamma_{6} D 3 R_{m t}^{2}+\varepsilon_{t}$

D1 represents the period before the most recent global financial crisis (Mar. 1998-Dec. 2007); D2 represents during the crisis itself (Jan. 2008-Dec. 2008); and after the crisis (Jan. 2009-May, 2013).The sample period is from Mar, 1998 to May, 2013. ** represents statistical significance at the $5 \%$ level.

\section{Conclusions}

This study examines investor's herding activity across China 30 provinces and cities (Beijing, Tianjin, Shanghai, Chongqing, Jilin, Heilongjiang, Liaoning, Hebei, Shandong, Jiangsu, Zhejiang, Fujian, Guangdong, Hainan, Guangxi, Anhui, Jiangxi, Hubei, Hunan, Sichuan, Guizhou,Yunnan, Henan, Shaanxi, Shanxi, Inner Mongolia, Gansu, Qinghai, Ningxia and Xinjiang) residential housing markets. To carry out the investigation, we apply monthly data from Mar.1998 to May.2013. We use Chang et al. (2000, CCK) method to examine the herding behavior. When the cross-sectional return dispersion (CSAD) increases or decreases at a decreasing rate in response to an increase in the aggregate market return, we will have evidence to say there is herding phenomena in the market. By using the quantile regression method, we find out the herding in the full sample periods; further, we find that when there are increasing in market return, the herding is stronger. During a decreasing market return, only in the periods of market turbulent, the investors will herd. Finally, we also show that during and after crisis period, the herding phenomenon is not obvious in China residential housing market. Herding is more likely to occur in pre-financial crisis period.

This paper is important for three main reasons. Firstly, to the best of our knowledge, we are the first to study the herding phenomena in China residential housing market across 30 provinces and cities by using quantile regression. Secondly, due to China residential housing market unique characteristics, the herding behavior in this market should be investigated. Thirdly, our study provides more importance herding behavior knowledge on China real estate market to practitioners, academia and policymakers. Together, these studies and contributions indicate that it is worthwhile to study the herding phenomena for Chinese housing market.

\section{References}

Banerjee, A. V. (1992). A simple model of herd behavior. Quarterly Journal of Economics, 57(3), 797-817. http://dx.doi.org/10.2307/2118364

Barnes, M., \& Hughes, A. W. (2002). A quantile regression analysis of the cross section of stock market returns. Working Paper, Federal Reserve Bank of Boston.

Bikhchandani, S., \& Sharma, S. (2000). Herd behavior in financial markets: A review. Work paper. International Monetary Funds.WP/00/48. Retrieved from http://www.imf.org/external/pubs/ft/wp/2000/wp0048.pdf

Bikhchandani, S., Hirshleifer, D., \& Welch, I. (1992). A theory of fads, fashion, custom, and cultural change as informational cascades. Journal of Political Economy, 100(5), 992-1026. http://dx.doi.org/10.2307/2138632

Buchinsky, M. (1998). Recent advances in quantile regression models: A practical guideline for empirical research. 
Journal of Human Resources, 33, 88-126. http://dx.doi.org/10.2307/146316

Chang, E., Cheng, J., \& Khorana, A. (2000). Examination of herd behavior in equity markets: An international perspective. Journal of Banking Finance, 24(10), 1651-1679. http://dx.doi.org/10.1016/S0378-4266(99)00096-5

Chiang, T. C., \& Zheng, D. (2010). An empirical analysis of herd behavior in global stock markets. Journal of Banking and Finance, 34(8), 1911-1121. http://dx.doi.org/10.1016/j.jbankfin.2009.12.014

Chiang, T. C., Li, J., \& Tan, L. (2010). Empirical investigation of herding behavior in Chinese stock markets: Evidence from quantile regression analysis. Global Finance Journal, 21(1), 111-124. http://dx.doi.org/10.1016/j.gfj.2010.03.005

Christie, W. G., \& Huang, R. D. (1995). Following the pied piper: Do individual returns herd around the market? Financial Analysts Journal, 51, 31-37. http://dx.doi.org/10.2469/faj.v51.n4.1918

CREIS. (2012). China real estate index system monthly report issue no. 201205.

Demirer, R., \& Kutan, A. M. (2006). Does herding behavior exist in Chinese stock markets? Journal of International Financial Markets, Institutions and Money, 16(2), 123-142 http://dx.doi.org/10.1016/j.intfin.2005.01.002

Diamond, D. W., \& Dybvig, P. H. (1983). Bank runs, deposit insurance, and liquidity. Journal of Political Economy, 91, 410-419. http://dx.doi.org/10.1086/261155

Graham, J. R. (1999). Herding among investment newsletters: Theory and evidence. Journal of Finance, 54, 237-268. http://dx.doi.org/10.1111/0022-1082.00103

Grinblatt, M., Titman, S., \& Wermers, R. (1995). Momentum investment strategies, portfolio performance, and herding: A study of mutual fund behavior. American Economic Review, 85, 1088-1105.

Koenker, R. (2005). Quantile regression. London: Cambridge University Press. http://dx.doi.org/10.1017/CBO9780511754098

Koenker, R. W., \& Bassett, G. Jr. (1978). Regression quantiles. Econometrica, 46, 33-50. http://dx.doi.org/10.2307/1913643

Lakonishok, J., Shleifer, A., \& Vishny, R. W. (1992). The impact of institutional trading on stock prices. Journal of Financial Economics, 32(1), 23-43. http://dx.doi.org/10.1016/0304-405X(92)90023-Q

Maug, E., \& Naik, N. (1996). Herding and delegated portfolio management: The impact of relative performance evaluation on asset allocation. Working paper, London Business School.

Newey, W., \& West, K. (1987). A simple, positive semi-definite, heteroskedasticity and autocorrelation consistent covariance matrix. Econometrica, 55, 703-708. http://dx.doi.org/10.2307/1913610

Scharfstein, D. S., \& Stein, J. C. (1990). Herd behavior and Investment. American Economic Review, 80(3), 465-479. http://dx.doi.org/10.1257/aer.90.3.705

Tan, L., Chiang, T. C., Mason, J., \& Nelling, E. (2008). Herding behavior in Chinese stock markets: An examination of $\mathrm{A}$ and $\mathrm{B}$ shares. Pacific-Basin Finance Journal, 16, 61-77. http://dx.doi.org/10.1016/j.pacfin.2007.04.004

Wermers, R. (1999). Mutual fund herding and the impact on stock prices. Journal of Finance, 54(2), 581-622. http://dx.doi.org/10.1111/0022-1082.00118

Zhou, J., \& Anderson, R. I. (2013). An empirical investigation of herding behavior in the U.S. REIT market. Journal of Real Estate Finance and Economics. http://dx.doi.org/10.1007/s11146-011-9352-x

Zhou, R., \& Lai, R. (2009). Herding and Information based trading. Journal of Empirical Finance, 16(3), 388-393. http://dx.doi.org/10.1016/j.jempfin.2009.01.004

\section{Copyrights}

Copyright for this article is retained by the author(s), with first publication rights granted to the journal.

This is an open-access article distributed under the terms and conditions of the Creative Commons Attribution license (http://creativecommons.org/licenses/by/3.0/). 